\title{
An Internet Plus Perspective Exploration of SPOC Teaching Mode for English Majors
}

\author{
Juanping Shao \\ School of Foreign Languages \\ Nanchang Institute of Technology \\ Nanchang, China 330099
}

\begin{abstract}
Internet plus Education" is a new form of education and it reflects the deep integration of the Internet and education. SPOC (Small Private Online Course) is a typical curriculum paradigm in the post MOOC era with characteristics of small, limited, intensive and so on. The SPOC teaching mode for English majors under the background of "Internet plus" will stimulate students' enthusiasm for learning and will undoubtedly improve students' autonomous learning ability and intercultural communicative competence.
\end{abstract}

Keywords-Internet plus; SPOC; MOOC; Teaching Mode

\section{INTRODUCTION}

At present, human society is in the period of transition to information society. With the emergence of new ideas and technologies, "Internet" has become a hot new concept. The Ministry of Education pinpointed in 2012 that we should set up scientific outlook on higher education development, take "quality promotion" as the core of the connotation development road, consolidate the basic position of undergraduate teaching and implement the teaching quality and teaching reform of undergraduate courses in Universities.

\section{PRESENT TEACHING Situation OF UndergRaduATE ENGLISH MAJORS}

In China, the English Majors in colleges and universities have nurtured a large number of excellent professionals and have, in different periods, made a due contribution to the social and economic development. However, with the rapid expansion of the scale, English major graduates are facing huge employment pressure, and the problems existing in the undergraduate education of English majors are becoming increasingly prominent. "Firstly, homogenization tendency is serious. English majors cover almost all types and levels of colleges and universities, but many of them lack of features. Secondly, characteristics are not prominent, and many people do not know what the characteristics of English Majors are. In their eyes, English major is to train students' listening, speaking, reading, writing and translating skills. In this way, it seems that there is no essential difference between English majors and English training institutions.

Acknowledgements: This paper is supported by Jiangxi Provincial Higher Education Teaching Reform Project "Research and Practice of SPOC Teaching for English Majors- An Internet Plus Perspective(JXJG16-18-12) \& Visiting Scholar Fund for Young and Middle-aged Core Teachers of Nanchang Institute of Technology.
Thirdly, the students' quality of English majors is in decrease, so it is difficult for English majors to meet social needs and shortages of high-end English talents are very severe. (Feng Guangwu, 2016:13)

In the international and globalized background of globalization, College English teaching is increasingly strengthened, and the number of social English training institutions is increasing as well. As a result, the English majors have lost the original advantages of English language skills. Meanwhile, the rapid development of society brings about higher requirements for English majors. All these have brought unprecedented pressure to English major undergraduate education. Under the background of deepening reform of Higher Education, only by following the times and the development of science and technology, by reforming the traditional educational concept, educational mode and educational means, by speeding up the training of teaching staff, by developing students' creative ability, self learning and lifelong learning ability, can we find a new development road.

As a result, in the background of the national strategic plan for the "Internet Plus" plan and in the era of diversification of talent cultivation, English major teaching must change the traditional teaching mode, actively integrate into the national higher education development strategy and actively explore the combination of the Internet and the development of education. By this way, we will cultivate high-level talents of English majors who can meet social requirements and adjust to new times.

\section{III. “INTERNET +EDUCATION"-INTEGRATION OF NEW IDEAS AND NEW TECHNOLOGY INTO TEACHING}

With the advent of the Internet era, the main form of information and knowledge change gradually from paper media to network media, and ways for people to obtain information and knowledge have also changed from printed materials to the Internet.(Wang Zhuli, Li Xiaoyu, Lin Jin: 2015) Early computer-assisted teaching depends mainly on the application of Multimedia Assisted Instruction System, such as computer, projector, amplification systems, etc. These facilities integrate video, audio, pictures, voice, text with contents, which provides great convenience for the teacher's classroom teaching, which gives students vivid, rich teaching content, and which brings a complete new feeling to 
the whole class. However, this kind of teaching mode still follows the traditional teaching pattern-"teachers stand on the platform to give the speech, students passively listen to the lecture under the platform". Still, students' learning initiative and learning potential can't be totally inspired.

Guidance of the State Council on Promoting the "Internet Plus Action" was introduced on July 4, 2015. It demands full use of the advantages of Internet's efficiency and convenience to improve the efficiency of resource utilization and to accelerate the development of an Internetbased education mode. There are different views and interpretations on the meaning and characteristics of "Internet Plus Education". Someone says that" Internet Plus Education" is a new form of education developed by means of modern information technology, such as network technology and multimedia technology. It is a new form of education that bases on modern electronic information and communication technology and it takes learners as the main body. (Wang Lei\&Zhou Ji, 2015:3-4). Some scholars believe that "Internet Plus Education' can realize the traditional education scale, and it can also realize the individualization of high quality education. It can achieve the fairness that everyone should have and it can also achieve high quality services that matches everyone's ability. ( $\mathrm{Yu}$ Shengquan, Wang Axi:2016)

The perspective of interpretation will be different, but it is undeniable that "'Internet Plus Education' is a new form of education that reflects the deep integration of the Internet and education. The progress of science and technology promotes education reform, so higher education must keep pace with the times.

\section{CURREnt Situation of SPOC Teaching AT Home AND ABROAD}

The informationalization of education has brought deep change for the reform of teaching mode. After the advent of the MOOC (Massive Open Online Course) teaching concept in 2009, foreign elite universities' MOOC courses, such as Harvard open class, Yale open class, begin to be introduced to our country. Domestic well-known universities have also launched the construction of MOOC courses. But, several years have passed and the limitations of the MOOC curriculum are also becoming more and more obvious. The most serious problems lie in the high cost and low click rate. Online self-study courses have not reached the expected effect. Peter E Sidorko, a scholar from the University of Hong Kong, compared the advantages and disadvantages of MOOC. In his opinion, both for students and for Universities, no prerequisites and no scale restrictions are the advantages as well as limitations of MOOC curriculum.

On the problem that brings about by large, open Internet teaching mode of MOOC, Harvard University, University of California, Berkeley, etc., all put forward another teaching mode, that is, SPOC (Small Private Online Course). The SPOC courses emphasize small, limiting, personalized online learning environment. SPOC teaching effect of top foreign universities promotes the exploration of SPOC teaching mode in China. In 2014, Kang Yeqin published a paper in Research On Education Tsinghua University that analyzed the concept and practice of SPOC mode and put forward the four advantages against MOOC teaching (Kang Yeqin:2014). Against the backdrop of SPOC continuous development, Universities in China have also shown great interest to actively participate in the research and application of SPOC.

\section{SPOC TEACHING DESIGN OF UNDERGRADUATE ENGLISH MAJORS ON THE BASIS OF INTERNET PLUS}

The task of higher education is to train advanced professionals with innovative spirit and practical ability. Profound changes are taking place in the teaching of undergraduate English majors which show the trend of digitalization of teaching resources, networking of teaching support and diversification of teaching methods. We must make full use of the advantages of professional features and network resources to explore the new way of construction on teaching resources and on teaching mode, and to build up a new teacher-student relationship.

\section{A. SPOC Instructional Design Principles under the Background of the "Internet Plus"}

SPOC teaching mode under the background of the "Internet Plus" is the integration of "Online learning" and "Classroom teaching" and in this mode, modern information technology is well applied to education. The purpose of teaching design is to maximize the students' learning potential and stimulate students' enthusiasm for learning to achieve the best learning effect. As a result, the teaching design under the background of the "Internet Plus" should adhere to the principle of teaching students in accordance with their aptitude and individualized learning, of taking the initiative of students as the core, of mobilizing the enthusiasm of students as the focus of learning to promote students to become the main body of knowledge construction.

\section{B. The Design of Teaching Mode}

Influenced by western culture, English majors are mostly extroverted, willing to accept new things, and to express their views in public. All these qualities provide a good condition for the smooth implementation of SPOC Teaching. Specifically, the teaching mode should include the following three steps: pre class instructional design in combination with online and offline classes, realization of teaching aim combined online learning with offline classroom discussion and exchange, and after-class evaluation of teaching effect both online and offline detection.

Under the traditional teaching mode, teachers are the center of the classroom teaching. Usually, teachers explain to students and students take notes, so the enthusiasm of active participation of students is not high. SPOC Teaching Mode for English Majors under the background of "Internet Plus" will make full use of network information' convenient, fast, sharing, rich, and other similar advantages, in combination with English majors' relatively solid knowledge of English and the quality that they can accept new things quickly, will combine online learning with offline learning, and will let students change from passive learning to active learning, from receptive learning to active, participatory, inquiry based, effective learning style. In the preliminary stage, teachers 
should have a scientific analysis on the learners, learning content and learning environment to give a reasonable guide for learners in the specific implementation process.

Before class, students should do self-study with the support of the SPOC platform. The teaching design before class is mainly arranged some targeted, specific teaching tasks by teachers. Students are divided into study groups with 3-5 students per group. Teachers provide students instructional video, related instructional resources and pre class exercises that are closely related to key points of knowledge. These materials should be targeted, clear, easy to understand and with moderate degree of difficulty. Students are required to use the spare time to complete those teaching resources. As for teaching video and teaching resources, they can be recorded together by the relevant teachers, or teachers and students can also find appropriate quality resources from online open education resources, such as Harvard open classes, Yale open classes, Khan College courses, Chinese national top-quality courses, and university open classes. Due to the special nature of language learning, design before class exercises should be open. Students can express themselves in English and they can also discuss, and show different views on any topic. The members of each team are expected to take their turn leading the study group. The one who is on duty summarizes team members view in writing materials or small videos and report the learning results online to the teacher and the class. In this way, it can not only raise the students' independent learning ability, but also train their cooperation and team spirit.

In class, teachers should be the organizer and guide of the class. Teachers and students carry out in-depth discussion face to face to solve difficult problems. The content design and time distribution of classroom are important. It should be composed of the following several aspects: to have a review of the content and exercises assigned by teachers before class, to further discuss questions refined by groups, and to sum up the key points of related knowledge. On the one hand, according to the materials submitted by the students on the SPOC platform before the class, the teacher finds out students difficult points in learning and refines typical questions for students to discuss in class. On the other hand, students seek ways to solve problems through collaboration, inquiry, teamwork, and so on to expand the depth and breadth of learning. Many texts for English Majors in the undergraduate textbooks are written by famous English and American writers. These texts have rich cultural background and there are many slangs and cultural allusions, and the structure and form of these English works are also quite different from those of Chinese. So, we students should discuss mutually in the learning process, search the Internet for information, communicate and write some study reports in English. In this way, English majors can not only improve statement and communication skills, but also cultivate their ability to find, sort out and refine English materials on the Internet and improve their cooperation ability and communication skills. This is also the goal of SPOC teaching mode.

After-class teaching reconsidering mainly consist in student' online practice test, a timely reflection on the knowledge of the learned units, and immediate evaluation. Online exercise tests can help students find out learning effects and difficult questions. In a timely reflection, teachers and students are required to publish their "teaching" and "learning" reflection in English on the SPOC online communication platform to share and to provide reference for the later teaching. About the immediate assessment, it refers to, on the SPOC platform and in the online space, student self-assessment, peer assessment and teacher assessment of students, students' evaluation on teachers. Through timely intervention, timely reflection, immediate evaluation, we can adjust and control the subsequent behavior of the respondents and maximize the effectiveness of learning. Timely reflection and immediate evaluation should reflect the principle of timeliness, incentive, comprehensiveness and fairness.

\section{CONCLUSION}

No doubt, the concept of "Internet plus Education" SPOC teaching mode combines modern information technology and international advanced educational idea. It is a useful attempt for English majors' education when it faces the bottleneck at present. This new teaching mode bases on Internet technology and Internet thinking mode and by means of deep integration between the Internet and traditional education, it will help teachers to play the guiding role, organizing role and coordinating role. This teaching mode will stimulate students' enthusiasm for learning and will undoubtedly improve English majors' self-study ability and intercultural communicative competence.

\section{REFERENCES}

[1] Feng Guangwu. The Current Reform in the English Major Programs: Review and Prospect[J]. Foreign Language World, 2016, (1):12-17.

[2] Kang Yeqin. An Analysis on SPOC: Post-MOOC Era of Online Education[J]. TsingHua Journal of Education, 2014, (1):85-93.

[3] Wang Lei, Zhou Ji. Internet plus Education[M].Beijing: CITIC Publishing Group,2015.

[4] Wang Zhuli, Li Xiaoyu, Lin Jin. Smartphones and the "Internet + Class": A New Thinking and New Pattern of Information Technology Integrated into Curriculum[J]. Journal of Distance Education, 2015, (4):14-21.

[5] Yu Shengquan, Wang Axi. The Transformation Path for "Internet + Education" [J]. China Educational Technology, 2016, (10):1-9. 